\title{
ESTUDO COMPARATIVO DO PROCESSO DE DESTILAÇÃO EXTRATIVA COM UTILIZAÇÃO DO MONOETILEGLICOL E 1- METILIMIDAZÓLIO CLORETO PARA DESIDRATAÇÃO DO ETANOL.
}

\author{
M. ALVES ${ }^{1}$, G. H. S. F. PONCE ${ }^{1}$, J. C. C. MIRANDA ${ }^{1}$, R. M. FILHO ${ }^{1}$ e M. R. W. MACIEL ${ }^{1}$ \\ ${ }^{1}$ Universidade Estadual de Campinas, Faculdade de Engenharia Química \\ E-mail para contato: wolf@feq.unicamp.br
}

\begin{abstract}
RESUMO - Este trabalho teve por objetivo avaliar os parâmetros operacionais do processo de destilação extrativa para desidratação do etanol. O processo de destilação extrativa é extensamente utilizado no setor sucroalcooleiro e utiliza como solvente o monoetilenoglicol. Neste trabalho, foi realizado o estudo comparativo da utilização do solvente 1-metilimidazólio cloreto (liquido iônico) com o solvente monoetilenoglicol (convencional). O uso do solvente 1- metilimidazólio cloreto apresentou uma redução de 41,2 \% de vazão mássica na corrente de alimentação de solvente, em relação ao monoetilenoglicol. Ocorreu acréscimo de $2,4 \%$ na energia total consumida nos refervedores das colunas de destilação ao se utilizar o 1- metilimidazólio cloreto ao invés do monoetilenoglicol. Outros parâmetros operacionais foram estudados neste trabalho, como: razões de refluxo, número de estágios teóricos e variação da temperatura das correntes de entrada. Foi utilizado para realização das simulações deste trabalho o simulador Aspen Plus®.
\end{abstract}

\section{INTRODUÇÃO}

O etanol é considerado um dos grandes combustíveis renováveis, e possíveis substitutos dos combustíveis fósseis não-renováveis. A produção mundial de etanol aproxima-se dos 83 bilhões de litros, dos quais 87 \% são produzidos nos Estados Unidos e no Brasil (RFA, 2014).

No Brasil, o incentivo para produção de etanol, como combustível automotivo começou com a implementação do Programa Nacional do Álcool (Proálcool), em 1975. O Proálcool estimulou a produção de veículos movidos a etanol hidratado, gerando aumento da produção de etanol hidratado pelas usinas sucroalcooleiras e reduzindo a dependência de combustíveis não renováveis (PARRO, 1996).

O etanol hidratado utilizado como combustível automotivo deve apresentar concentração de 92,6 a 93,8\% de etanol em massa, conforme a norma vigente brasileira (ANP, 2011). Essa concentração descrita pela ANP (2011) é próxima do ponto de azeótropo da mistura etanol/água, que é de 95,6\%, em massa, à pressão atmosférica (GMEHLING et al., 1982). 


\section{9 a 22 de outubro de 2014 \\ Florianópolis/SC}

Em 1992, a produção de etanol anidro, usando como base o etanol hidratado, passou a ganhar destaque como substituinte do poluente chumbo tetraetila, utilizado até então como aditivo à gasolina (BRASIL, 2008). A porcentagem desta adição aumentou de 5\%, na década de 1930, para 25\%, em volume, atualmente (MISTÉRIO DA AGRICULTURA, 2014).

Nas unidades de desidratação do etanol obtém-se o etanol anidro, que para ser comercializado como combustível deve possuir teor alcoólico mínimo de 99,3\%, em massa, segundo as normas da Agência Nacional de Transportes do Brasil (ANP, 2011).

A destilação convencional não possibilita a produção de etanol anidro, sendo necessário um processo alternativo para que possa ser alcançada uma concentração de etanol acima do ponto de azeotropia. Os métodos alternativos de separação mais utilizados para produção de etanol anidro a partir do etanol hidratado são: destilação azeotrópica, pervaporação (membranas), adsorção em peneiras moleculares (zeólitas) e destilação extrativa (VANE, 2008).

A destilação extrativa, que é o foco deste trabalho, envolve a adição de um terceiro componente de menor volatilidade do que os componentes da mistura etanol/água a serem separados (DIAS, 2008).

Na separação de componentes na destilação extrativa utilizam-se duas colunas de destilação. A primeira coluna, chamada de coluna extrativa, tem a função de "quebrar" o azeótropo, mudando a volatilidade relativa dos componentes, enquanto que a segunda coluna, chamada de coluna de recuperação, é utilizada para recuperar o solvente utilizado no processo (BRITO, 1997). Esse sistema foi implantado em 2001, utilizando como solvente o monoetilenoglicol (MEG) (MEIRELLES, 2006).

Jaimes Figueroa (2011) relata o uso doe líquidos iônicos (LI) como substituto ao monoetilenoglicol. Os líquidos iônicos apresentam como vantagem ser compostos pouco voláteis, benignos ambientalmente do ponto de vista de sua baixa volatilidade, e podem ser usados para diminuir a poluição ambiental, por esse motivo são chamados de componentes "verdes". Os LI têm se tornado uma alternativa para substituição de chamados compostos orgânicos voláteis; que são solventes tradicionalmente usados na indústria (ROGERS e SEDDON, 2003).

\section{EQUIPAMENTOS}

O processo de destilação extrativa é formado basicamente por duas colunas de destilação em série, denominadas colunas de destilação extrativa e coluna de recuperação, além de trocador de calor e bomba hidráulica. Na sequência, tem-se um breve resumo sobre cada um desses equipamentos.

Coluna de destilação extrativa (EXTRACAO): essa é a coluna em que é produzido o etanol anidro, sendo alimentada com o etanol hidratado (no fundo) e o solvente (no topo). O etanol anidro é produzido no topo da coluna, saindo com a concentração de 99,7\% em massa, enquanto a mistura entre solvente e água sai no fundo da coluna. A mistura solvente/água é enviada pra outra coluna que fará a separação dessa mistura.

Coluna de recuperação (RECUP): nessa coluna é realizada a separação solvente/água que 
provem da destilação extrativa. Como a água apresenta ponto de ebulição e pressão de vapor menor que o solvente, ela é retirada no topo da coluna de recuperação, enquanto o solvente é retirado no fundo dessa coluna e apresenta concentração acima de 99,0 \%, em massa.

Condensador (TRO-CLR): tem a função de reduzir a temperatura do produto de topo da coluna, que passa do estado vapor para líquido condensado. O condensador opera de forma análoga aos trocadores de calor, mas utiliza, preferencialmente, a água como material de troca térmica da corrente fria.

Make up (MEG-PURO): no processo existe a corrente de make up (compensação), que provem de um tanque com solvente puro, possuindo a função de repor as perdas de solvente do processo. No simulador a corrente de make up e a corrente de reciclo são adicionadas junto ao misturador (mixer) para alimentação de solvente na coluna extrativa.

Os equipamentos estão representados na Figura 1.

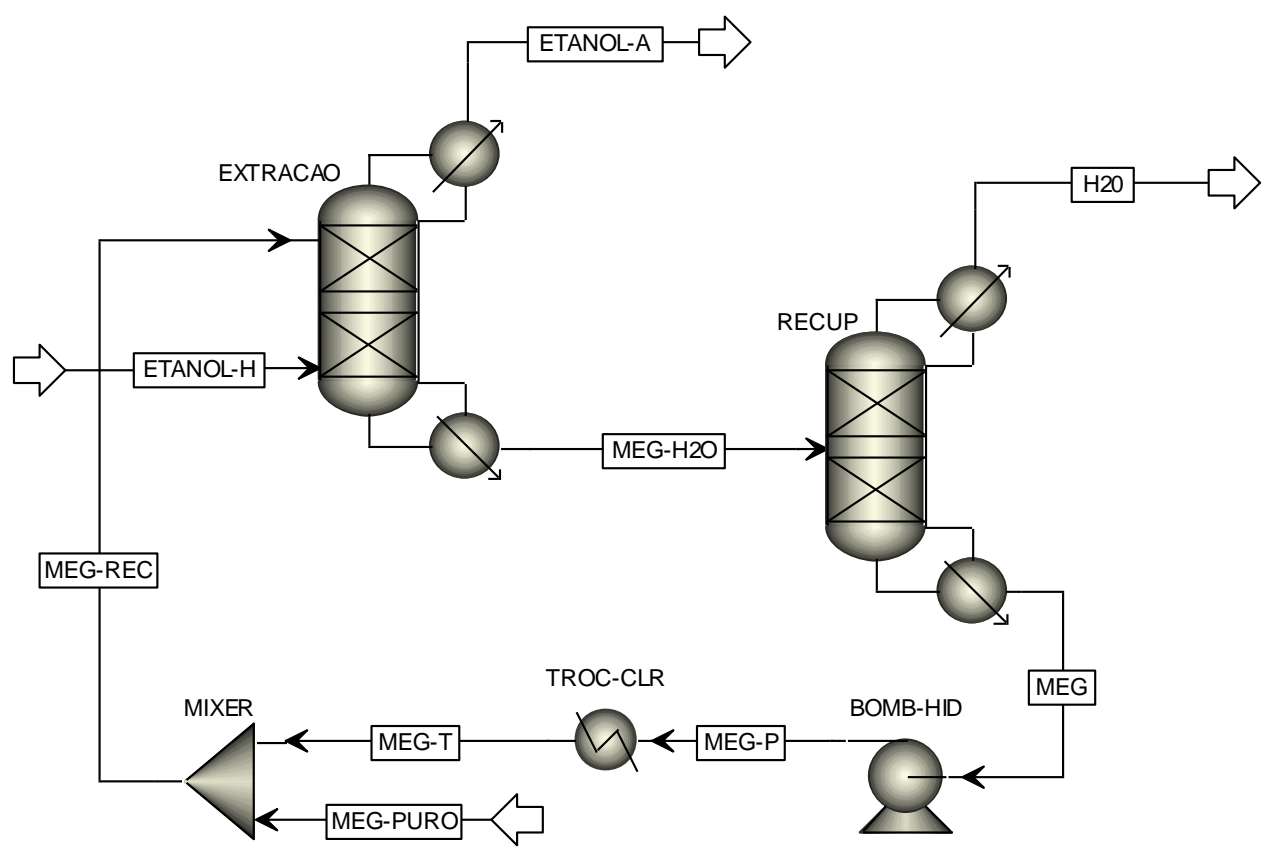

Figura 1 - Representação da simulação do processo de destilação extrativa realizada pelo simulador Aspen Plus®.

\section{PARÂMETROS UTILIZADOS NAS SIMULAÇÕES}

As simulações foram realizadas com base em uma usina sucroalcooleira que processa 500 toneladas de cana por hora. CGEE - Centro de Gestão e Estudos Estratégicos (2009) assume que o fator de conversão é de 85,0 litros de etanol por tonelada de cana. Neste caso, para a moagem de cana e fator de conversão assumido por CGEE (2009), tem-se que a produção é igual a 42.500 litros de 
etanol hidratado por hora, dado utilizado neste trabalho para a alimentação da coluna extrativa, e concentração de etanol hidratado igual a 93,0 \% em massa.

Foram realizados dois casos de estudo e comparados os desempenhos dos parâmetros do processo ao serem utilizados os solventes monoetilenoglicol, no primeiro caso, e o líquido iônico 1metilimidazólio cloreto, no segundo caso. Para os dois casos foi estabelecido que a concentração de etanol anidro como sendo de $99,7 \%$, em massa.

Os cálculos realizados para este trabalho, por meio do simulador Aspen Plus®, são representados pelo modelo termodinâmico NRTL (Non-Randow Two-Liquid) - RK (Redlich-Kwong) entre as fases.

Os parâmetros operacionais são descritos nas Tabelas 1 e 2.

Tabela 1 - Parâmetros de operação das colunas de destilação do processo de desidratação do etanol, utilizando como solvente o monoetilenoglicol e 1-metilimidazólio cloreto.

\begin{tabular}{|c|c|c|}
\hline Especificações & Coluna Extrativa & Coluna de Recuperação \\
\hline Número de estágios & 35 & 20 \\
\hline Pressão da coluna (kPa) & 101,3 & 101,3 \\
\hline Posição de alimentação & $\begin{array}{cc}\text { Etanol hidratado } & 33 \\
\text { Solvente } & 3\end{array}$ & 4 \\
\hline Temperatura de entrada $\left({ }^{\circ} \mathrm{C}\right)$ & $\begin{array}{l}\text { Etanol hid. } 81,7 \\
\text { Solvente } \\
110,0\end{array}$ & - \\
\hline Tipo de condensador & Total & Total \\
\hline Razão de refluxo & 1,0 & 0,3 \\
\hline Vazão de alimentação & & \\
\hline Vazão de destilado (kg/hr) & 39630 & - \\
\hline Vazão de produto de fundo $(\mathrm{kg} / \mathrm{hr})$ & - & 25495 \\
\hline
\end{tabular}

Tabela 2 - Parâmetros de operação dos equipamentos no processo de destilação extrativa.

Equipamento

\begin{tabular}{lc} 
Bomba hidráulica & \\
Eficiência da bomba & 0,75 \\
Eficiência mecânica da bomba & 0,99 \\
Pressão de descarga $(\mathrm{kPa})$ & 101,3 \\
Condensador & \\
Temperatura de saída $\left({ }^{\circ} \mathrm{C}\right)$ & 110,0 \\
Pressão de operação $(\mathrm{kPa})$ & 101,3 \\
Make-up & \\
Pressão $(\mathrm{kPa})$ & 101,3 \\
Temperatura $\left({ }^{\circ} \mathrm{C}\right)$ & 110,0 \\
\hline
\end{tabular}


Os dados referentes ao monoetilenoglicol foram obtidos do banco de dados do simulador Aspen Plus®. O liquido iônico 1-metilimidazólio cloreto não possui parâmetros no banco de dados no simulador Aspen Plus ${ }^{\circledR}$, sendo assim, alguns dados foram buscados na literatura para que a simulação fosse realizada. Os dados referentes ao 1-metilimidazólio cloreto, em relação à densidade, à temperatura de ebulição e à massa molar, foram reportados por Lopes e Padua (2006) e Guidechem (2014).

Shen et al. (2011) estudaram o efeito do liquido iônico 1 - metilimidazólio cloreto ([MIm]Cl) no equilíbrio líquido-vapor na mistura etanol/água. Shen et al. (2011) calcularam pelo modelo NRTL a pressão de vapor para o sistema ternário, com base em parâmetros de interação binária, mostrados na Tabela 3.

Tabela 3 - Apresentação dos coeficientes de interação binária para a mistura etanol/água e 1metilimidazólio cloreto.

\begin{tabular}{lccccc}
\hline \multicolumn{1}{c}{ Sistema binário } & $\begin{array}{c}\mathrm{A}_{\mathrm{ij}} \\
(\mathrm{J} / \mathrm{mol})\end{array}$ & $\begin{array}{c}\mathrm{A}_{\mathrm{ij}} \\
(\mathrm{cal} / \mathrm{mol})\end{array}$ & $\begin{array}{c}\mathrm{A}_{\mathrm{ji}} \\
(\mathrm{J} / \mathrm{mol})\end{array}$ & $\begin{array}{c}\mathrm{A}_{\mathrm{ij}} \\
(\mathrm{cal} / \mathrm{mol})\end{array}$ & $\alpha_{\mathrm{ij}}$ \\
\hline$\{$ Água (i) + Etanol $(\mathrm{j})\}$ & 5615,84 & 1341,32 & $-511,16$ & $-122,09$ & 0,30 \\
$\{$ Água (i) + [MIm]Cl $(\mathrm{j})\}$ & 362,36 & 86,55 & $-6692,57$ & $-1598,49$ & 0,43 \\
$\{$ Etanol (i) + [MIm]Cl $(\mathrm{j})\}$ & 3332,73 & 796,01 & $-3602,46$ & $-860,43$ & 0,30 \\
\hline
\end{tabular}

Os dados reportados da literatura em relação ao 1-metilimidazólio cloreto foram inseridos no simulador Aspen Plus ${ }^{\circledR}$ por meio do módulo Pseudocomponent e Dechema deste simulador.

\section{RESULTADOS}

A Tabela 4 mostra os principais resultados referentes à simulação de processo de destilação extrativa, utilizando monoetilenoglicol e o líquido iônico 1-metilimidazólio cloreto.

Tabela 4 - Apresentação dos resultados referentes ao processo de destilação extrativa, usando como solvente o monoetilenoglicol e o líquido iônico.

\begin{tabular}{lcc}
\hline Especificações & $\begin{array}{c}\text { Solvente } \\
\text { monoetilenoglicol }\end{array}$ & $\begin{array}{c}\text { Solvente } \\
\text { 1-metilimidazólio cloreto }\end{array}$ \\
\hline Coluna Extrativa & & \\
Consumo de solvente na coluna extrativa $(\mathrm{kg} / \mathrm{h})$ & 25.500 & 15.000 \\
Razão de refluxo (em massa) & 1,0 & 0,9 \\
Número de estágios teóricos & 35 & 35 \\
Energia consumida no refervedor $(\mathrm{kWh} / \mathrm{t}$ et.) & 191,92 & 179,67 \\
Coluna de Recuperação de Solvente & & 0,3 \\
Razão de refluxo (em massa) & 0,3 & 12 \\
Número de estágios teóricos & 15 & 100,70 \\
Energia consumida no refervedor $(\mathrm{kWh} / \mathrm{t}$ et.) & 82,14 & 279,67 \\
$\begin{array}{l}\text { Energia total consumida nos refervedores } \\
(\mathrm{kWh} / \mathrm{t} \text { et.) }\end{array}$ & 274,06 & \\
\hline
\end{tabular}




\section{9 a 22 de outubro de 2014 \\ Florianópolis/SC}

Os resultados mostraram que o consumo de solvente na coluna extrativa foi de $25.500 \mathrm{~kg} / \mathrm{h}$ para o monoetilenoglicol, enquanto que para o 1-metilimidazólio cloreto, o consumo de $15.000 \mathrm{~kg} / \mathrm{h}$. O consumo do 1-metilimidazólio cloreto na coluna extrativa representa a redução de $41,2 \%$ em relação ao consumo de monoetilenoglicol.

A proporção em massa (razão $\mathrm{S} / \mathrm{F}$ ) de líquido iônico em relação à massa de etanol hidratado foi de $35,3 \%$, enquanto que a razão de monoetilenoglicol relação à massa de etanol hidratado foi de 60,0 $\%$.

A razão S/F para o líquido iônico esta dentro do valor recomendado por Ullmann e Elvers (2011), tais autores relatam que, para que se tenha uma suficiente separação, na destilação, deve haver uma razão $\mathrm{S} / \mathrm{F}$ de 30 a 50\%, em massa.

A Tabela 4 revela a vantagem de utilizar o líquido iônico no processo de destilação extrativa em relação ao uso do monoetilenoglicol. Ao ser utilizado o liquido iônico, foi apresentado menor razão de refluxo, para a coluna extrativa, e menor quantidade de número de estágios teóricos, para a coluna de recuperação, obtendo a mesma concentração de produtos finais para os diferentes solventes.

A energia total dos refervedores apresentou resultados semelhantes em relação à utilização dos dois solventes neste trabalho, com acréscimo de $2,4 \%$ ao se utilizar o 1- metilimidazólio cloreto ao invés do monoetilenoglicol.

A variação da temperatura da corrente de entrada teve influência somente no gasto energético do refervedor. Para maiores temperaturas das correntes de entrada de etanol hidratado ou de solvente, o consumo de energia do refervedor diminuiu. Para o aumento da temperatura de etanol hidratado de $80^{\circ}$ para $120^{\circ} \mathrm{C}$ houve o decréscimo do gasto de energia no refervedor igual $10,5 \%$.

\section{CONCLUSÃO}

Este trabalho teve por objetivo a comparação de um solvente alternativo ao monoetilenoglicol para a desidratação do etanol. Os resultados descrevem algumas vantagens comparativas quando da utilização do 1- metilimidazólio cloreto em relação ao monoetilenoglicol para o processo de destilação extrativa. Uma das vantagens é a redução de $25.500 \mathrm{~kg} / \mathrm{h}$ de monoetilenoglicol para 15.000 $\mathrm{kg} / \mathrm{h}$ de 1-metilimidazólio cloreto, representando a redução de 41,2 \% da carga de solvente adicionada na coluna extrativa, ao ser utilizado o líquido iônico.

Segundo preços de aquisição obtidos da empresa Sigma-Aldrich, o 1-metilimidazólio cloreto apresenta valores de custo 5,14 vezes maiores em relação ao monoetilenoglicol, para a mesma quantidade de solvente em massa (SIGMA-ALDRICH, 2014). Mesmo com valor de mercado do 1metilimidazólio cloreto sendo 5,14 maior que o monoetilenoglicol, o líquido iônico pode apresentar vantagens devido seu ponto de ebulição $\left(231,7^{\circ} \mathrm{C}\right)$ ser maior que o do monoetilenoglicol $\left(197,3{ }^{\circ} \mathrm{C}\right)$, dessa maneira uma menor reposição de solvente se faz necessária no processo, o que, a longo prazo, traz uma redução de custo ao se utilizar o 1-metilimidazólio cloreto. Além disso, a utilização do líquido iônico propicia uma efetiva diminuição no custo de projeto uma vez que uma menor 
quantidade de número de estágios teóricos se fazem necessárias na coluna de recuperação de solvente.

Ademais, os resultados da simulação mostraram um menor valor de razão de refluxo na coluna extrativa ao se utilizar como solvente o 1- metilimidazólio cloreto, sendo que, o valor total da energia consumida nos refervedores ao se utilizar o 1- metilimidazólio cloreto foi 2,4\% maior do que quando utilizou-se o monoetilenoglicol.

Por fim, os resultados mostraram que os parâmetros operacionais não sofreram relativas mudanças ao ser utilizado o líquido iônico, exceto pela menor vazão mássica de líquido iônico na alimentação da coluna extrativa.

\section{REFERENCIAS}

ANP - Agência Nacional de Petróleo, Gás Natural e Biocombustíveis. Resolução ANP No 7, de 09/02/2011 - Publicada no Diário Oficial da União em 10/02/2011 - Retificada no Diário Oficial da União 14/04/2011.

CGEE - CENTRO DE GESTÃO E ESTUDOS ESTRATÉGICOS. Bioetanol combustível: uma oportunidade para o Brasil. Brasília: Centro de Gestão e Estudos Estratégicos, 2009.

DIAS, M. O. S. Simulação do processo de produção de etanol a partir do açúcar e do bagaço, visando à integração do processo e a maximização da produção de energia e excedentes do bagaço. Dissertação (Doutorado em Engenharia Química) - Faculdade de Engenharia Química, Universidade Estadual de Campinas. Campinas, 2008.

GMEHLING, J.; ONKEN, U.; ARLT, W. Vapor-liquid equilibrium data collection - organic hydroxy compounds: alcohols. Frankfurt: DECHEMA, 1982.

GUIDECHEM - CHEMICAL TRADING GUIDE. Chemical Dictionary: CAS n 35487-17-3. Disponível em: <http://www.guidechem.com/dictionary_keys_35487-17-3-p1.html>. Acesso em: janeiro de 2014.

JAIMES FIGUEROA, J. E. Análise e otimização do processo de obtenção do etanol anidro, empregando líquidos iônicos. Dissertação (Mestrado em Engenharia Química) - Faculdade de Engenharia Química, Universidade Estadual de Campinas. Campinas, 2011.

LOPES, J. N. C. e PADUA, A. A. H. Molecular force field for ionic liquids III: imidazolium, pyridinium, and phosphonium cations; chloride, bromide, and dicyanamide anions. The Journal of Physical Chemistry B, v. 110, n. 39, 19586-19592, 2006.

MEIRELLES, A. J. A. Expansão da produção de bioetanol e melhoria tecnológica da destilação alcoólica. In: FAPESP. Workshop do Projeto Diretrizes de Políticas Públicas para a Agroindústria Canavieira do Estado de São Paulo: Produção de etanol. Lorena, 2006.

MINISTÉRIO DA AGRICULTURA, PECUÁRIA E ABASTECIMENTO. Mistura carburante 
automotiva (etanol anidro/gasolina) - Cronologia. Disponível em: <http://www.agricultura.gov.br/arq_editor/file/Desenvolvimento_Sustentavel/Agroenergia/Orientacoe s_Tecnicas/01-Mistura\%20etanol\%20anidro-gasolina-CRONOLOGIA(Atualiz_02_09_2011).pdf >. Acesso em: janeiro de 2014.

PARRO, J. S. A visão do setor automobilístico. In: Fernandes, E. S. L.; Coelho S. T. Perspectivas do álcool combustível no Brasil. São Paulo: USP - Instituto de Eletrotécnica e Energia, 1996. 166 p.

RFA - Renewable Fuels Association. 2013 Ethanol Industry Outlook: battling for the Barrel. Disponível em: <http://www.ethanolrfa.org/pages/annual-industry-outlook> acesso em: janeiro de 2014.

ROGERS, R.; SEDDON, K. Ionic liquids - Solvents of the future? Science, v. 302, p. 792-793, 2003.

SHEN, C.; LI, X.; LU, Y.; LI, C. Effect of ionic liquid 1-methylimidazolium chloride on the vapour liquid equilibrium of water, methanol, ethanol, and $\{$ water + ethanol $\}$ mixture. The Journal of Chemical Thermodynamics, n. 43, 1748-1753, 2011.

SIGMA-ALDRICH CO. Disponível em: < http://www.sigmaaldrich.com/brazil.html > acesso em: junho de 2014.

VANE, L. M. Separation technologies for the recovery and dehydration of alcohols from fermentation broths. Biofuels, Bioproducts and Biorefining, v.2, p. 553-588, 2008. 